\title{
Integrating family planning and reproductive health information into livelihood training programs for young people in Souhag
}

Evidence Project

Follow this and additional works at: https://knowledgecommons.popcouncil.org/departments_sbsr-rh How does access to this work benefit you? Let us know!

\section{Recommended Citation}

Evidence Project. 2021. "Integrating family planning and reproductive health information into livelihood training programs for young people in Souhag," infographic. Washington, DC: Population Council, The Evidence Project. 
Integrating Family Planning

and Reproductive Health

Information Into Livelihood

Training Programs for

Young People in Souhag

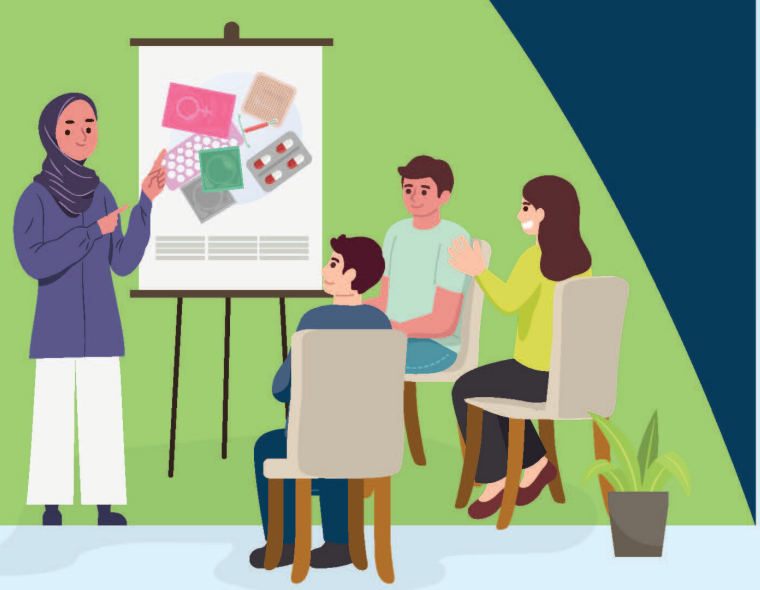

Goal: To increase demand for private family planning and reproductive health (FP/RH) services among young people (18-35 years) in urban Souhag.'

\section{Intervention}

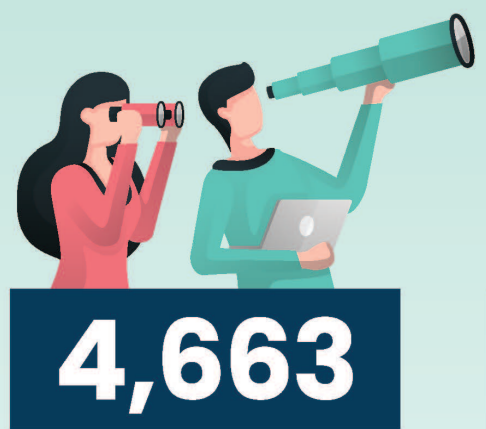

male and female

job seekers

(18-35 years)

in six districts in

Souhag received

five days of integrated FP/RH

livelihood training

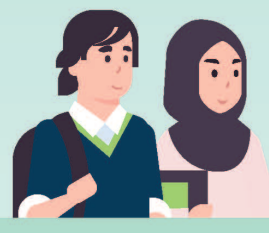

Male and female peer educators delivered the training and shared posters, fliers, and booklets with participants

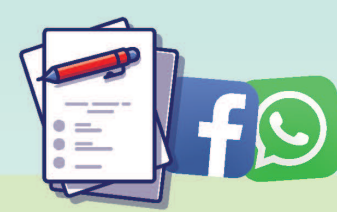

Participants also received FP/RH messages through social media platforms (Ma3looma Facebook page and WhatsApp groups)

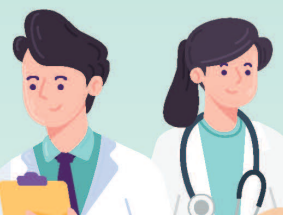

\section{Peer educators} shared with participants the names and contact information of private doctors and pharmacists who had been trained by the project in FP/RH service provision 


\section{Porticiponts' Perspectives²}

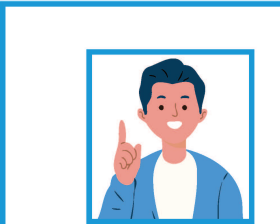

"I mean, there are many benefits to family planning and birth spacing. I never knew what family planning meant. I always thought it meant having one child, that's it. It's all about having children at the right time. That was good information."

Male participant, 32 years old
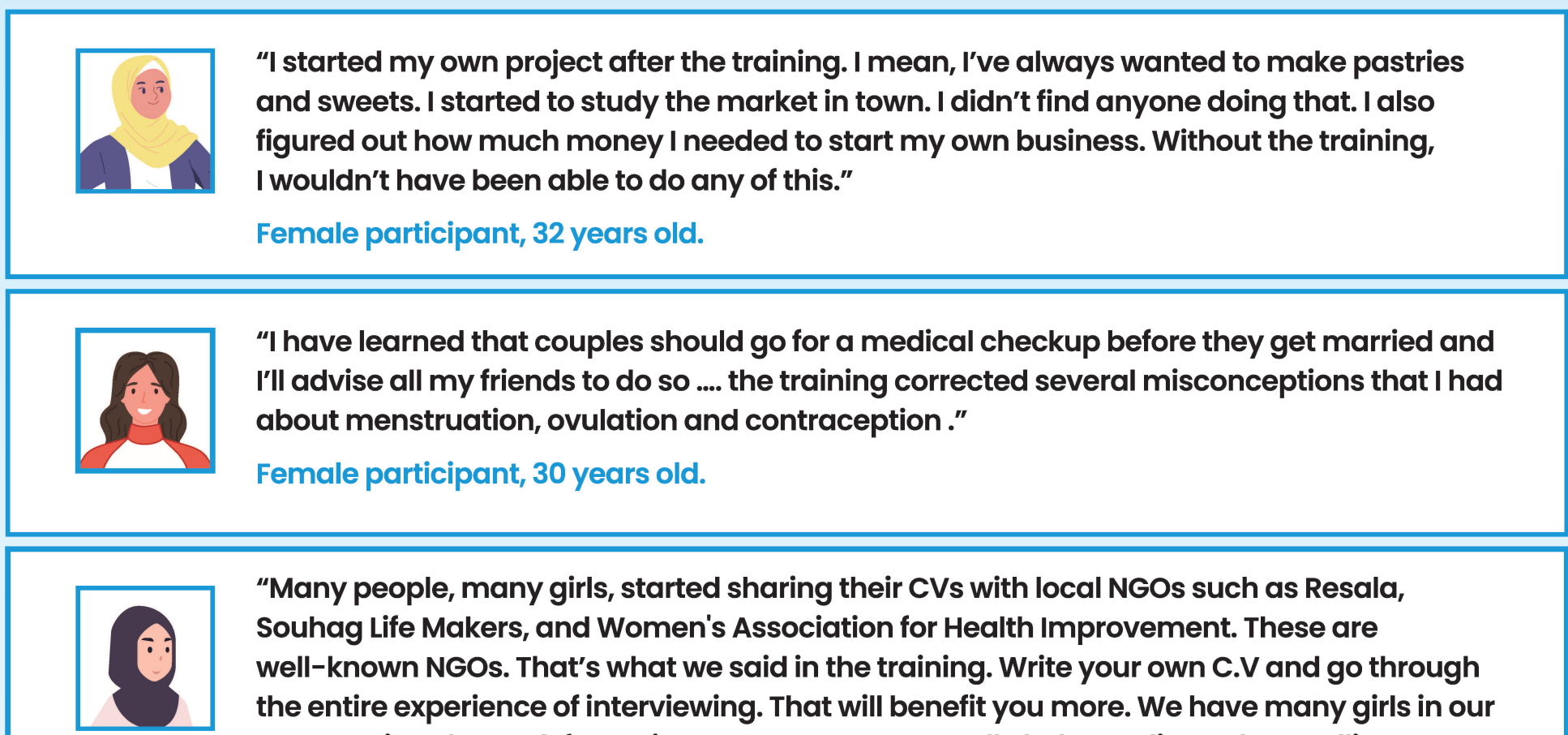

“Many people, many girls, started sharing their CVs with local NGOs such as Resala, Souhag Life Makers, and Women's Association for Health Improvement. These are well-known NGOs. That's what we said in the training. Write your own C.V and go through the entire experience of interviewing. That will benefit you more. We have many girls in our community who work for various NGOs now, some sell clothes online, others selling furniture and household appliances!"

Female participant, 29 years old.

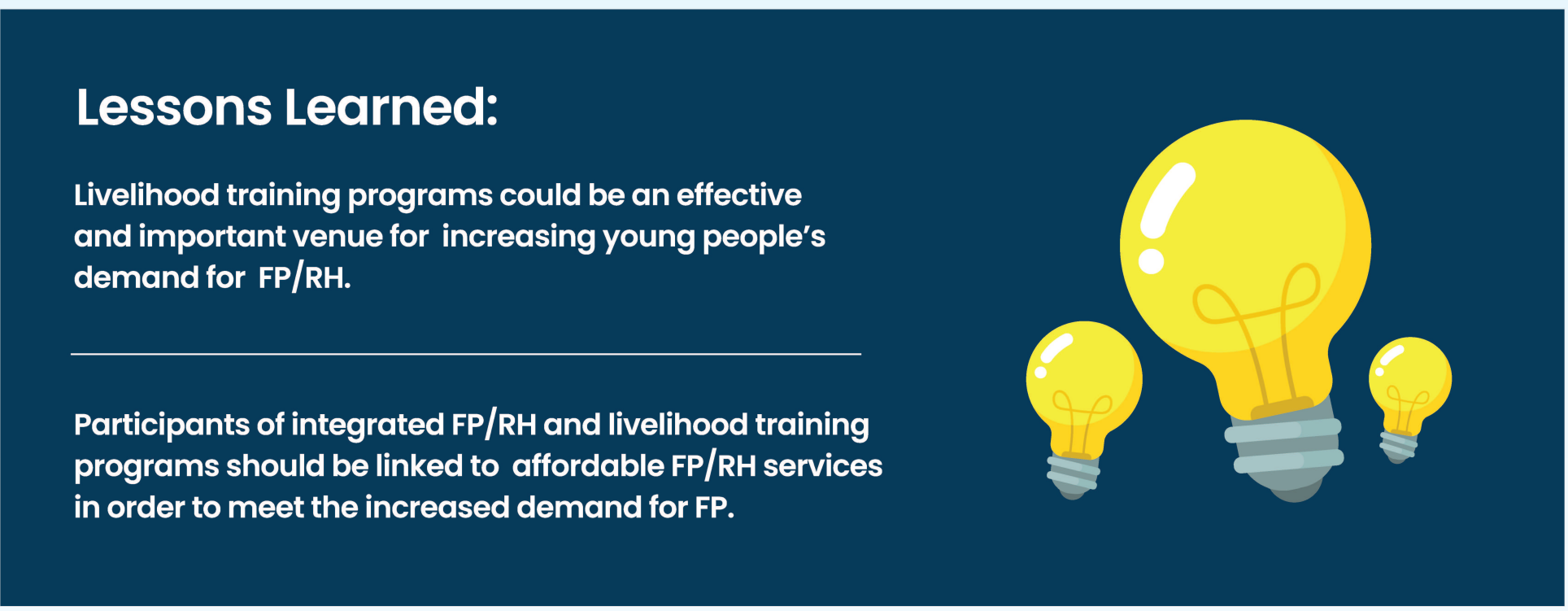

To learn more about the effects of the intervention on young people's knowledge, attitudes and practices regarding family planning, please check: Abdel-Tawab, Nahla, Norhan Bader, Elizabeth Tobey, and Aparna Jain. 2020. “Two implementation models of workers' health education programs in Egypt: What works? What doesn't work?" Research Brief. Washington DC: Population Council, The Evidence Project.

\section{USAID}

Evidence
The Evidence Project is made possible by the generous support of the American people through the United States Agency for International Development (USAID) under the terms of cooperative agreement no. AID-OAA-A-13-00087. The contents of this document are the sole responsibility of the Evidence Project and the Population Council and do not necessarily reflect the views of USAID or the United States Government.

The Evidence Project uses implementation science-the strategic generation, translation, and use of evidence-to strengthen and scale up family planning and reproductive health programs to reduce unintended pregnancies worldwide. The Evidence Project is led by the Population Council. C) 2021, The Population Council, Inc. 